Article

\title{
Experimental Research on Regeneration Characteristic of ED Regeneration for Lithium Bromide Desiccant Solution with High Concentration: Operating Condition and Electrode Solution
}

\author{
Qing Cheng ${ }^{1,2}$ and Han Wang ${ }^{1,2, *}$ \\ 1 Jiangsu Province Key Laboratory of Aerospace Power System, Nanjing 210016, China; \\ chengqingny@njtech.edu.cn \\ 2 School of Energy Science and Engineering, Nanjing Tech University, Nanjing 211816, China \\ * Correspondence: wangh_njt@njtech.edu.cn
}

Received: 11 August 2020; Accepted: 8 September 2020; Published: 11 September 2020

check for updates

\begin{abstract}
Electrodialysis is regarded as a novel liquid regeneration method, and the regenerated solution can satisfy the dehumidification requirements even in a hot and humid environment. $\mathrm{LiBr}$ solution is an important choice for a liquid desiccant air conditioning system due to its great dehumidifying ability, so it is necessary to conduct experimental exploration of the regeneration characteristics of $\mathrm{ED}$ regeneration for $\mathrm{LiBr}$ solution. In this paper, the effects of solution concentration, circulation flow rate, current and electrode solution on the performance of the electrodialysis regeneration system were studied by constructing an experimental electrodialysis regeneration system. The results show that growing the starting concentration of the LiBr solution adversely affects the regeneration characteristics of the electrodialyzer and of the air conditioning system dehumidified by the solution. Under test conditions, as the initial concentration of LiBr solution increased from $45 \%$ to $55 \%$, the performance coefficient (COP) of the system decreased from 2.12 to 1.05. When the dehumidification requirement is met, the initial concentration of the LiBr solution should be reduced. Increasing the circulating flow rate can improve the regeneration performance of the electrodialyzer and the capability of the air conditioning system dehumidified by the solution, but excessively increasing the circulating flow rate will decrease the regeneration performance of the electrodialyzer and the performance of the air conditioning system dehumidified by the solution. Increasing the current can increase the concentration of the $\mathrm{LiBr}$ solution in the regeneration cells in a short time, but it will reduce the regeneration performance of the electrodialyzer and the characteristic of the air conditioning system dehumidified by the solution. The current needs to be minimized when meeting regeneration requirements. With the growth in the flow rate of the electrode solution, the regeneration performance of the electrodialyser decreases continuously.
\end{abstract}

Keywords: liquid desiccant; regeneration; electrodiaalysis; LiBr; electrode solution

\section{Introduction}

Due to high energy loss of buildings' air conditioning systems, improving the energy efficiency of buildings plays a vital role in reducing global energy use. In the past few decades, in order to promote building energy conservation, much research has been done in the application and development of sustainable and green technologies [1,2]. Liquid desiccant dehumidification technology has received widespread attention due to its high energy saving potential [3,4], and this technology has been practically applied in the air dehumidification of buildings. 
In the air conditioning system dehumidified by a solution, regeneration of the dehumidification solution is key to ensuring the continuous work of the air conditioning system dehumidified by the solution $[5,6]$. The current thermal regeneration method is the main means of regenerating desiccant solutions. The thermal regeneration method whose heat source comes from heat pumps, waste, and solar energy has been extensively discussed $[7,8]$. However, when the outside environment is hot and humid, the desiccant solution needs more heat energy and higher temperature in order to be regenerated, and the hot desiccant solution after heat regeneration needs to be cooled before it can work to meet the dehumidification requirement. This shortage limits the widespread application of liquid desiccant air conditioning systems utilizing the thermal regeneration method.

In addition to the thermal regeneration method, the electrodialysis (ED) technology for desiccant solutions is also a reliable method. Electrodialysis technology is mainly used in chemical, food, pharmaceutical, seawater desalination, wastewater treatment, and ion separation fields $[9,10]$. The application of electrodialysis for desiccant solution regeneration was first proposed by Li et al. [11]. It is found that, through theoretical analysis, the electrodialysis regeneration method is more stable than the thermal regeneration method because the weather conditions do not affect the performance of the electrodialyzer. Cheng et al. [12] also proposed a two-stage photovoltaic electrodialysis regeneration system. Theoretical analysis found that the two-stage regeneration system has more energy efficiency than the single stage under reasonable operating conditions. After this, Cheng et al. [13-15] conducted a series of experimental studies on electrodialysis regeneration for $\mathrm{LiCl}$ solution, and the results showed that when a $5 \mathrm{~A}$ current was used to regenerate the dehumidification solution, the temperature of the dehumidification solution did not rise above $3^{\circ} \mathrm{C}$; at the same time, the regeneration performance of the electrodialyzer was obviously affected by the concentration difference. Al-Jubainawi et al. [16] carried out experiments using an electrodialyzer with 10 membrane pairs and numerically simulated the regeneration process of the electrodialyzer using COMSOL Multiphysics. Li and Zhang [17] found that the current intensity and solute concentration were the key factors affecting the regeneration performance of the electrodialyzer.

At present, lithium chloride is the main solution for the experimental study of electrodialysis regeneration of desiccant solutions, and experimental exploration of the regeneration of lithium bromide solution with high concentrations by an electrodialyzer is rarely conducted. Li and Zhang [17] conducted a theoretical study on the performance of electrodialysis regeneration systems using different desiccant solutions and found that the characteristic of the electrodialysis regeneration system utilizing $\mathrm{LiBr}$ solution is better than those of lithium chloride $(\mathrm{LiCl})$ and calcium chloride $\left(\mathrm{CaCl}_{2}\right)$ at the same current efficiency performance. Liu et al. [18] analyzed and compared the mass transfer performance between two common hygroscopic salt solutions ( $\mathrm{LiBr}$ solution and $\mathrm{LiCl}$ solution) and humid air, and the study showed that the dehumidification characteristic of lithium bromide ( $\mathrm{LiBr})$ is better than $\mathrm{LiCl}$ when the two solutions are used under the same treatment conditions.

However, when the $\mathrm{LiBr}$ solution and the $\mathrm{LiCl}$ solution have the same dehumidifying ability, the concentration of the $\mathrm{LiBr}$ solution is higher than that of $\mathrm{LiCl}$. The literature data so far show that the solution concentration is the key factor affecting the regeneration characteristic of ED. Therefore, the characteristic of the electrodialyzer to regenerate lithium bromide and lithium chloride is also very different, so it is necessary to conduct experimental exploration of the regeneration characteristic of ED regeneration for $\mathrm{LiBr}$ solution. On the other hand, electrode solution is significant for the regeneration characteristic of ED, so it is also important to study the effect of electrode solution on the regeneration characteristic of $\mathrm{ED}$ for $\mathrm{LiBr}$ solution with a high concentration.

This paper focuses on studying the effects of $\mathrm{LiBr}$ solution concentration, flow rate, current, and electrode solution on the regeneration characteristic of the electrodialyzer to regenerate lithium bromide solution and to analyze the regeneration performance of the electrodialysis regeneration system for LiBr solution based on the experimental data. 


\section{Method}

\subsection{Electrodialysis Method}

In an electrodialyzer, cation-exchange membranes (CMV) and anion-exchange membranes (AMV) are alternately placed between a cathode and an anode. An example of an electrodialyzer with one membrane pair is shown in Figure 1.

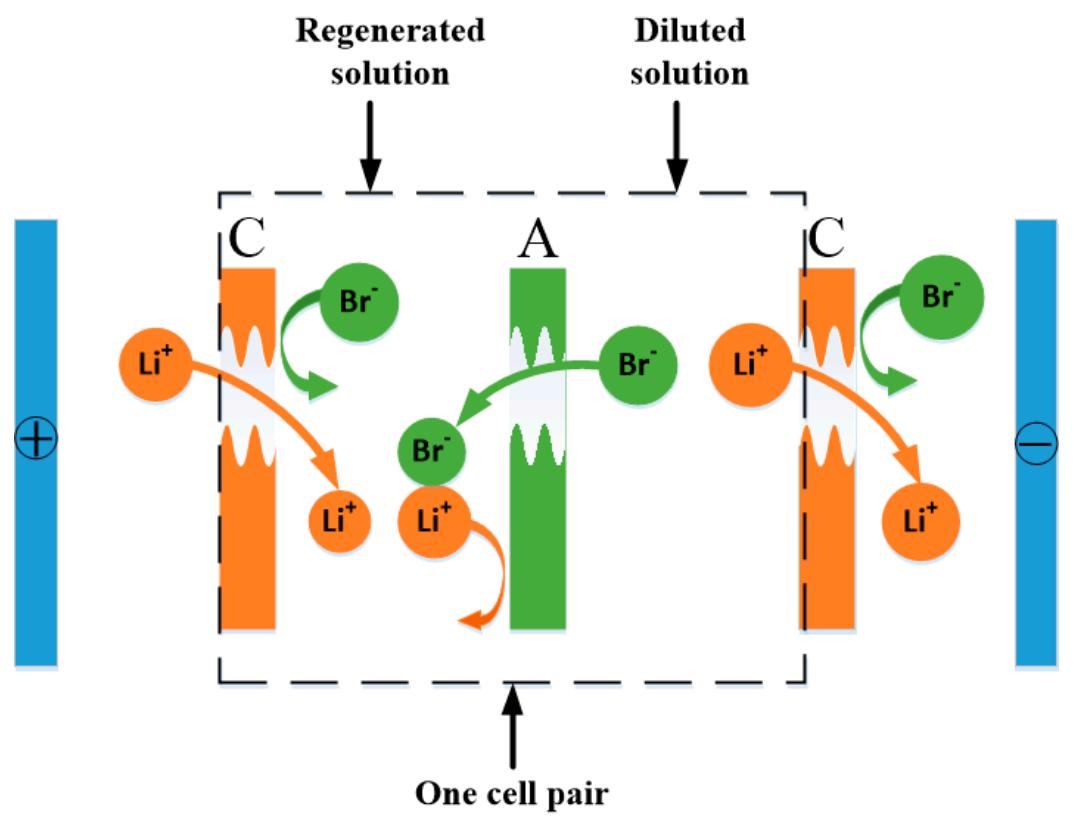

Figure 1. Schematic diagram of electrodialyzer.

Under the effect of electric field force, $\mathrm{Br}^{-}$moves to the anode through the membranes of anion exchange, and $\mathrm{Li}^{+}$moves to the cathode through the membranes of cation exchange. During the migration process, the membranes of anion exchange only allow $\mathrm{Br}^{-}$to pass and retain $\mathrm{Li}^{+}$; the membranes of cation exchange only allow $\mathrm{Li}^{+}$to pass and retain $\mathrm{Br}^{-}$. So, the concentration of the LiBr solution in the regenerate panels will increase and the concentration of the LiBr solution in the dilute panels will decrease. The concentrated $\mathrm{LiBr}$ solution in the regenerate panels flows into the regeneration solution tank, and the dilute $\mathrm{LiBr}$ solution in the dilute panel flows into the desalination solution tank. Finally, the concentrated $\mathrm{LiBr}$ solution required in the air conditioning system dehumidified by solution can be obtained in the regeneration solution tank.

\subsection{Test Device}

A simplified schematic of the experimental setup is shown in Figure 2. The electrodialysis regeneration system is mainly composed of an electrodialyzer and a rectifier. The system also includes three circulation pumps, three solution tanks, and three flow meters, which are used in the three circulation circuits of regeneration, desalination, and electrodes. The electrodialyzer is the core device of the test. The electrodialyzer used in this test consists of 30 membrane pairs, and the effective size of the membrane is $200 \times 100 \mathrm{~mm}$. In this experimental system, an AMV anion-exchange membrane and CMV cation-exchange membrane (both supplied by AGC) are applied. Meanwhile, the thickness of the regeneration panel and the desalination panel of the electrodialyzer was $1 \mathrm{~mm}$. 


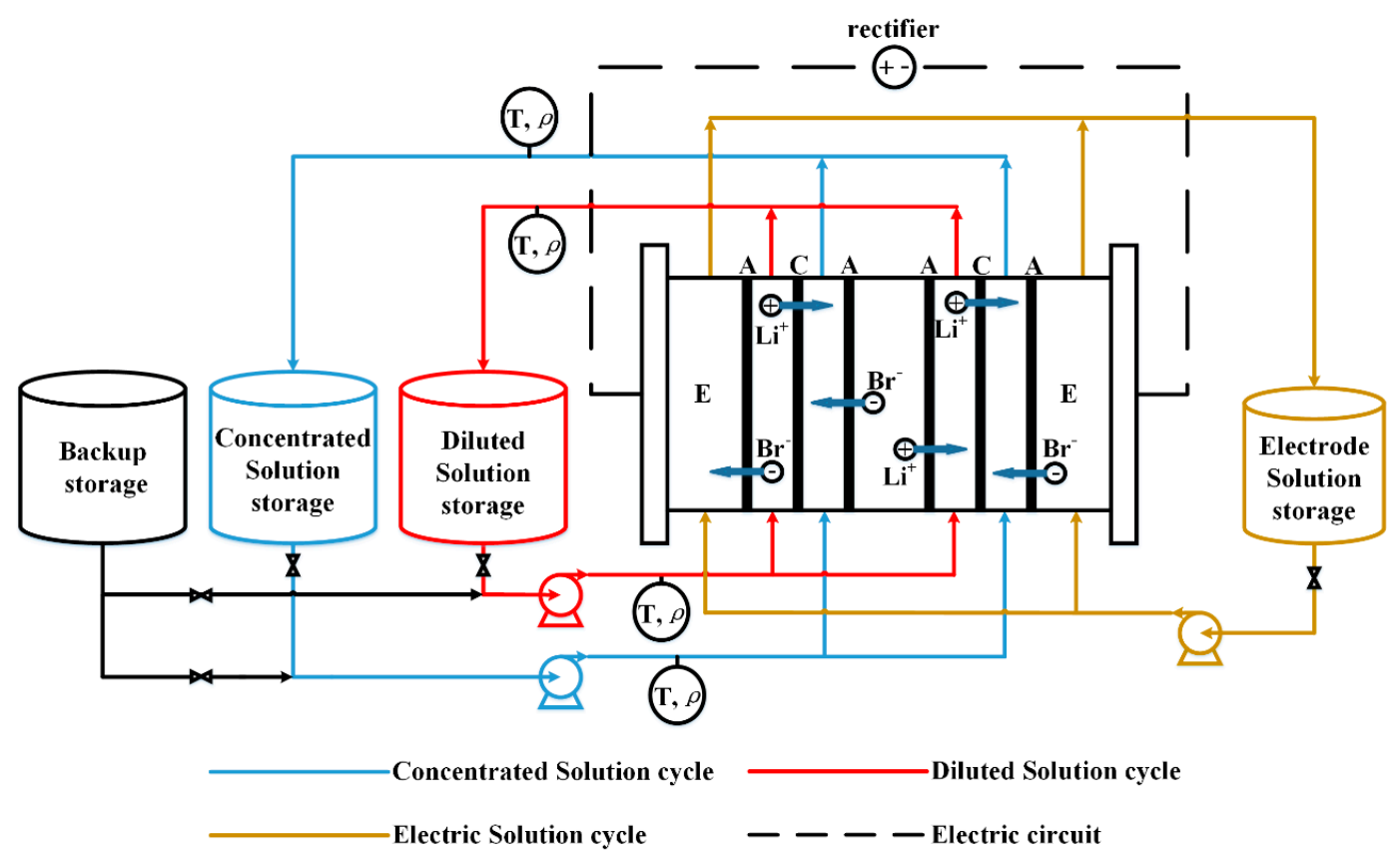

Figure 2. Schematic diagram of electrodialyzer.

During the experiment, in order to calculate the concentration of the LiBr solution, the density and temperature of the lithium bromide solution need to be measured. The purity of LiBr used in the test was over $99 \%$. The main measuring instruments and their measurement accuracy are shown in Table 1 . In the analysis of the experiment results, the average values of testing parameters have been employed for evaluating the regeneration characteristic of the ED regenerator.

Table 1. Test instrument and accuracy.

\begin{tabular}{cccc}
\hline Name & Model & Test Dimension & Accuracy \\
\hline Rectifier & HCP-DC & $0-20 \mathrm{~A}$ & $\pm 0.01 \mathrm{~A}$ \\
Density meter & AU-120L & $0.0001-99.9999 \mathrm{~g} / \mathrm{cm}^{3}$ & $0.0001 \mathrm{~g} / \mathrm{cm}^{3}$ \\
Thermocouple & TC-TT-T-30-5M & $-200-350{ }^{\circ} \mathrm{C}$ & $\pm 0.5^{\circ} \mathrm{C}$ \\
Flowmeter & LFS15 & $16-160 \mathrm{~L} / \mathrm{h}$ & $\pm 5 \mathrm{~L} / \mathrm{h}$ \\
Data acquisition instrument & Agilent 34970A & - & - \\
\hline
\end{tabular}

For concentration calculation, the relative uncertainty can be determined by Equation (1) [19].

$$
\frac{\delta y}{y}=\frac{\sqrt{\sum_{n}^{i=1}\left(\frac{\delta y}{\delta x_{i}} \delta x_{i}\right)^{2}}}{y}
$$

in which $\frac{\delta y}{y}$ is relative uncertainty, $y$ is the variable, $x_{i}$ is the independent measured variable, $n$ is the number of independent measured variables.

According to Equation (1), the maximum composite relative uncertainty of the LiBr solution concentration in the experiment is $0.383 \%$.

\subsection{Test Scheme}

Twenty-six tests were selected and divided into 3 groups, as shown in Table 2, to explain the effect of solution concentration, flow rate, current, and electrode solution on the performance of the electrodialysis regeneration system for $\mathrm{LiBr}$ solution regeneration. In this scheme, values of current and flow rate of desiccant solutions are calculated in the design stage of the ED regenerator; 
the initial concentration of desiccant solutions is based on the dehumidification requirement under different environment climates. In Table 2, flow rate in panels includes the flow rates of desiccant solution in all panels, including electrode chambers. Each test was run for $66 \mathrm{~min}$, and all experiments were performed continuously under ambient conditions. During the experiment, the density and temperature of the inlet and outlet solutions of the regeneration panel and the desalination panel were measured every $6 \mathrm{~min}$, and the rectifier voltage was recorded.

Table 2. Test conditions.

\begin{tabular}{cccc}
\hline Serial Number & $\begin{array}{c}\text { Flow Rate in Panels } \\
\text { (L/h) }\end{array}$ & Current (A) & $\begin{array}{c}\text { Initial Concentration of } \\
\text { Desiccant Solution (\%) }\end{array}$ \\
\hline \multirow{2}{*}{ Group 1 } & 80 & 5 & $45,50,55$ \\
& $80,120,160$ & 5 & 50 \\
Group 2 & 80 & $3,5,8$ & 50 \\
\hline \multirow{2}{*}{ Group 3 } & 80 & 5 & $27,35,42$ \\
& $80,120,160$ & 5 & 35 \\
& 80 & $3,5,8$ & 35 \\
\hline
\end{tabular}

\subsection{Analytical Method for Experiment}

The concentration variety of the $\mathrm{LiBr}$ solution in the regeneration panels is a significant index for evaluating the regeneration performance of the electrodialysis and can be obtained by the following methods:

$$
C_{\text {cadd }}=C_{\text {oreg }}-C_{\text {ireg }}
$$

in which $C_{\text {cadd }}$ is the concentration difference at the outlet and inlet of the regeneration panels of the electrodialyzer, $C_{\text {oreg }}$ is the concentration of $\mathrm{LiBr}$ solution exiting the regeneration panels, $C_{\text {ireg }}$ is the concentration of $\mathrm{LiBr}$ solution entering the regeneration panels.

Current efficiency is also a crucial evaluation parameter of the electrodialysis regeneration system, which is the ratio of the charge transferred by the ion to the total charge applied to the electrodialyzer. It can be calculated by the following equation:

$$
\zeta=\frac{z F m_{\text {reg }}\left(C_{\text {oreg }}-C_{\text {ireg }}\right)}{I N M_{d}}
$$

in which $z$ is solution valence, $F$ is Faraday constant, $\mathrm{C} / \mathrm{mol}, m_{\text {reg }}$ is the flow rate of concentrated solution, $\mathrm{kg} / \mathrm{s}$; I is operating current of electrodialysis, $\mathrm{A}, \mathrm{N}$ is membrane logarithm of electrodialysis regenerator; $M_{d}$ is molar mass of solution, $\mathrm{kg} / \mathrm{mol}$.

The operating cost of an electrodialysis regeneration system for desiccant solution is mainly dependent on the electricity costs of the electrodialysis regenerator and solution pump. The operating cost of the solution pump is ignored in the following studies, as it is much lower than the operating cost of the electrodialyzer. Therefore, the theoretical operating cost of an electrodialysis regeneration system for desiccant solution can be obtained as follows:

$$
P_{l}=\left[\frac{z F m_{\text {reg }}\left(C_{\text {oreg }}-C_{\text {ireg }}\right)}{\zeta M_{d}}\right]^{2} \times \frac{\left(R_{\text {am }}+R_{c m}+\frac{L_{r}}{A_{e} \rho_{\text {reg }}}+\frac{L_{r}}{A_{e} \rho_{\text {diu }}}\right)}{N}
$$

in which $R_{c m}$ is the resistance of the anion-exchange membrane, $\Omega, R_{a m}$ is the resistance of the cation-exchange membrane, $\Omega, L_{r}$ is the thickness of one regeneration panel, $\mathrm{m}, A_{e}$ is the effective transfer area of the membrane, $\mathrm{m}^{2}, \rho_{\text {reg }}$ is the conductivity of the regenerate solution, $\mathrm{s} / \mathrm{m}, \rho_{\text {diu }}$ is the 
conductivity of the desalination solution, $\mathrm{s} / \mathrm{m}$. The experimental operating cost of an electrodialysis regeneration system for desiccant solution can be obtained as follows:

$$
P_{s}=U I
$$

Note that $U$ is the rectifier voltage, $\mathrm{V}$, in the formula.

The dehumidification capacity of the electrodialysis regeneration system for desiccant solution can be described by the following equation:

$$
Q_{r}=\frac{r_{w} m_{\text {reg }}\left(C_{\text {oreg }}-C_{\text {ireg }}\right)}{C_{\text {ireg }}}
$$

in which $r_{w}$ is the latent heat of vaporization of water, $\mathrm{kJ} / \mathrm{kg}$.

Therefore, the theoretical and experimental performance coefficient (COP) of the electrodialysis regeneration system for desiccant solution is as follows:

$$
\begin{gathered}
C O P_{l}=\frac{Q_{r}}{P_{l}}=\frac{r_{w w} m_{\text {reg }}\left(C_{\text {oreg }}-C_{\text {ireg }}\right)}{\left[\frac{z F m_{\text {reg }}\left(C_{\text {oreg }}-C_{\text {ireg }}\right)}{\zeta M_{d}}\right]^{2}} \times \frac{N}{C_{\text {ireg }}\left(R_{\text {am }}+R_{c m}+\frac{L_{r}}{A_{e} \rho_{\text {reg }}}+\frac{L_{r}}{A_{e} \rho_{\text {diu }}}\right)} \\
C O P_{s}=\frac{Q_{r}}{P_{s}}=\frac{r_{w} m_{\text {reg }}\left(C_{\text {oreg }}-C_{\text {ireg }}\right)}{U I C_{\text {ireg }}}
\end{gathered}
$$

\section{Results and Discussion}

\subsection{Effect of Initial Concentration}

The regeneration performance of the electrodialyzer with different initial concentrations is shown in Figure 3a. When the initial lithium bromide concentration was increased from $45 \%$ to $55 \%$, the current efficiency of the electrodialyzer to regenerate the lithium bromide solution decreased from $14.72 \%$ to $10.73 \%$. At the end of the experiment, the lithium bromide solution concentration in the regeneration tank decreased from $0.408 \%$ to $0.224 \%$ with the increase of the initial lithium bromide concentration. This is due to the increase in the initial concentration, which continuously increases the viscosity of the lithium bromide solution, which leads to a decrease in the regeneration performance of the electrodialysis regenerator.

The effects of the initial concentration of LiBr solution in the electrodialysis regeneration system on the energy consumption and COP of the system under theoretical and experimental conditions are respectively shown in Figure 3b,c. When the initial concentration of $\mathrm{LiBr}$ solution was increased from $45 \%$ to $55 \%$, the energy consumption of the system increased slightly under theoretical conditions, and the theoretical COP of the system decreased from 9.17 to 5.46 .

Under test conditions, as the initial concentration of $\mathrm{LiBr}$ solution was raised from $45 \%$ to $55 \%$, the energy consumption of the system increased rapidly from 50 to $107.5 \mathrm{~W}$; the COP of the system decreased from 2.12 to 1.05 . The main reason for this is that, when the concentration of the lithium bromide solution is between $45 \%$ and $55 \%$, the conductivity of the lithium bromide decreases as the concentration increases, which leads to an increase in the resistance of the electrodialyzer and an increase in energy consumption during regeneration. 

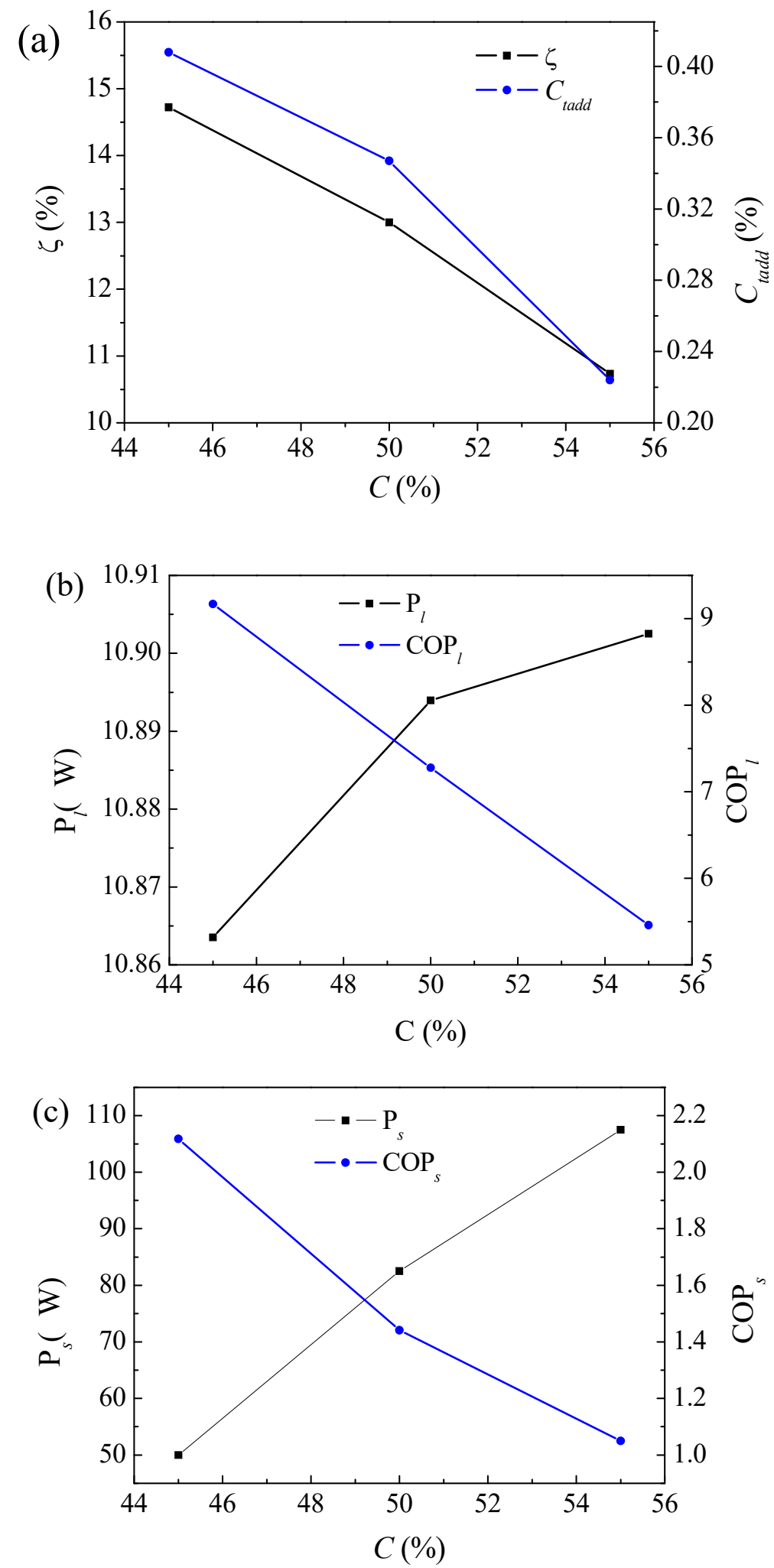

Figure 3. (a) Effect of initial concentration on regeneration performance of electrodialyzer; (b) effect of initial concentration on performance of electrodialysis regeneration system under theoretical conditions; (c) effect of initial concentration on performance of electrodialysis regeneration system under experimental conditions. 


\subsection{Effect of Flow Rate}

The regeneration performance of the electrodialyzer as a function of flow rate is discussed. As we can see from Figure 4a, the current efficiency of the electrodialyzer appears to increase first and then decrease when the flow rate is continuously increased. With the flow rate increased from 80 to $160 \mathrm{~L} / \mathrm{h}$, the current efficiency of the electrodialyzer to regenerate the lithium bromide solution increased from $13 \%$ to $15.83 \%$ and then decreased to $12.23 \%$. Ultimately, the concentration of the lithium bromide solution in the regeneration tank first increased and then decreased. When the flow rate was 80,120 , and $160 \mathrm{~L} / \mathrm{h}$, the concentration increase was $0.347 \%, 0.386 \%$, and $0.294 \%$, respectively. Properly increasing the flow rate can enhance the regeneration performance of the electrodialyzer by improving the diffusing performance between ions on the boundary of membrane and ions in the mainstream of the liquid desiccant, but excessively increasing the flow rate will reduce the time for the mainstream of the liquid desiccant to stay in the electrodialyzer, and the ions will not have enough time to pass through the membrane, which will reduce the regeneration performance of the electrodialyzer.

The effects of solution flow rate in the channel on the system energy consumption and system performance under the theoretical and experimental conditions in ED regeneration for LiBr solution are respectively shown in Figure $4 b$,c. Increasing the flow rate can save energy for the system.

Under theoretical conditions, when the inlet flow rate is increased from 80 to $160 \mathrm{~L} / \mathrm{h}$, the energy consumption of the system is basically unchanged, and the system performance tends to increase first and then decrease. The maximum system COP can reach 10.49. Under the test conditions, when the flow rate was increased from 80 to $160 \mathrm{~L} / \mathrm{h}$, the system energy consumption decreased from 82.5 to $78 \mathrm{~W}$. As the flow rate increases, the system performance tends to increase first and then decrease. When the flow rates are 80,120 , and $160 \mathrm{~L} / \mathrm{h}$, the system COPs are $0.624,0.780$, and 0.60 , respectively. This is because the regeneration performance of the electrodialyzer increases first and then decreases owing to the increase in the inlet flow rate, but the energy consumption decreases with the change in the flow rate. Therefore, when the electrodialyzer is used to regenerate the dehumidifying solution, an appropriate solution flow rate should be selected so that the electrodialyzer has the desired performance.

\subsection{Effect of Current}

Under various applied currents, the current efficiency of the electrodialyzer to regenerate the lithium bromide solution and the incremental change in the solution concentration in the regeneration tank are shown in Figure 5a. When the current was increased from 3 to 8A, the current efficiency of the electrodialyzer decreased from $17.45 \%$ to $10.2 \%$; at the end of the experiment, the solution concentration in the regeneration tank increased from $0.259 \%$ to $0.484 \%$. This shows that a large current can lead to an increase in the concentration of the desiccant solution in a short time, but it will cause the regeneration performance of the electrodialyzer to decrease.

The effects of current on the performance of the system and energy consumption under the theoretical and experimental conditions of the electrodialysis regeneration system for LiBr solution are respectively shown in Figure $5 b$,c. With the increase in current, the energy consumption of the system increases rapidly under both theoretical and experimental conditions, and the COP of the system continues to decrease. When the current is increased from 3 to $8 \mathrm{~A}$, the system energy consumption increases from 3.915 to $27.84 \mathrm{~W}$ under theoretical conditions, and the system performance coefficient decreases from 16.237 to 3.584 ; under the experimental conditions, the system energy consumption increases from 30.9 to $189.6 \mathrm{~W}$, and the system performance decreases from 2.073 to 0.523 . 

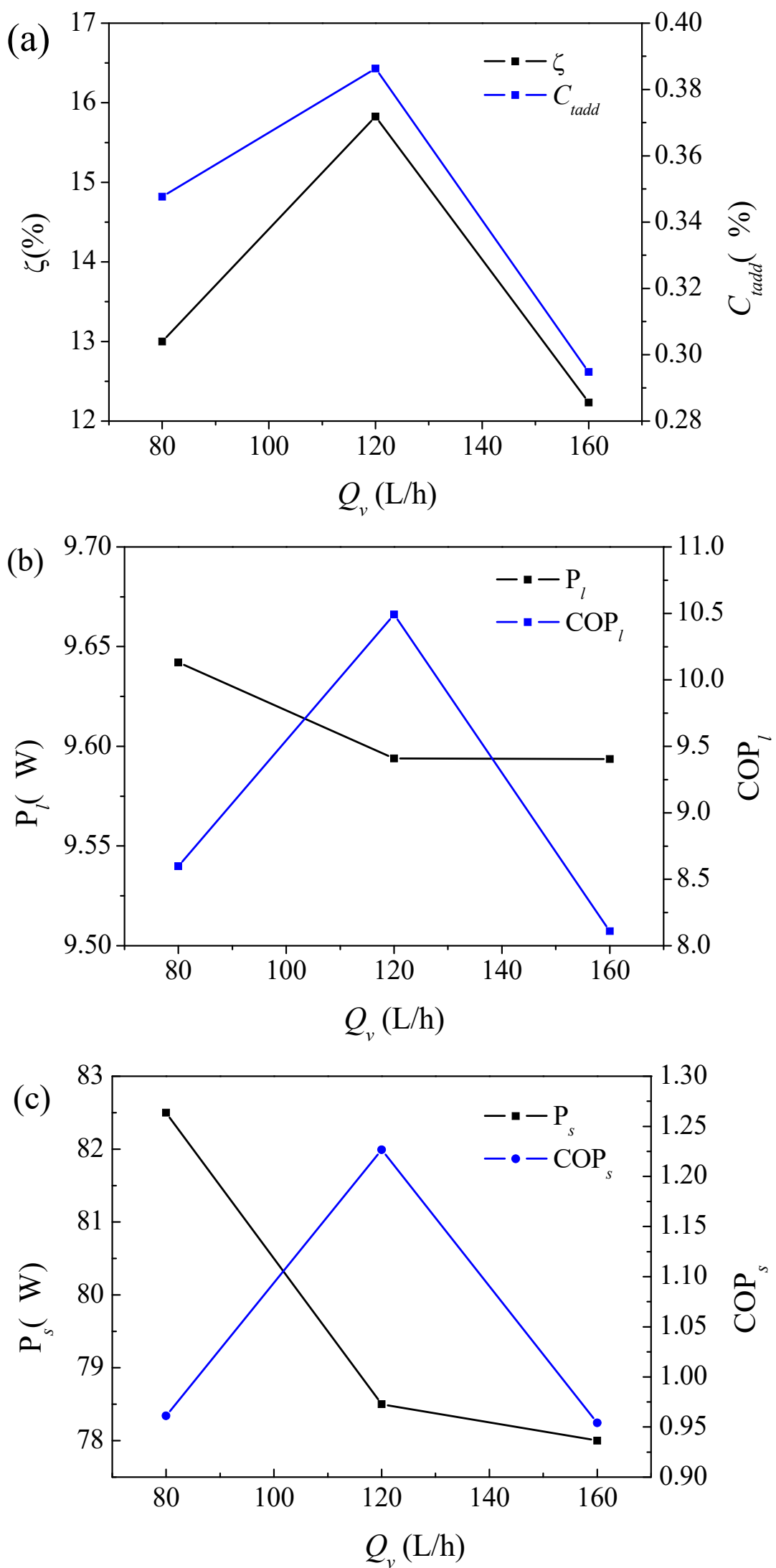

Figure 4. (a) Effect of flow rate on regeneration performance of electrodialyzer; (b) effect of flow rate on performance of electrodialysis regeneration system under theoretical conditions; (c) effect of flow rate on performance of electrodialysis regeneration system under test conditions. 

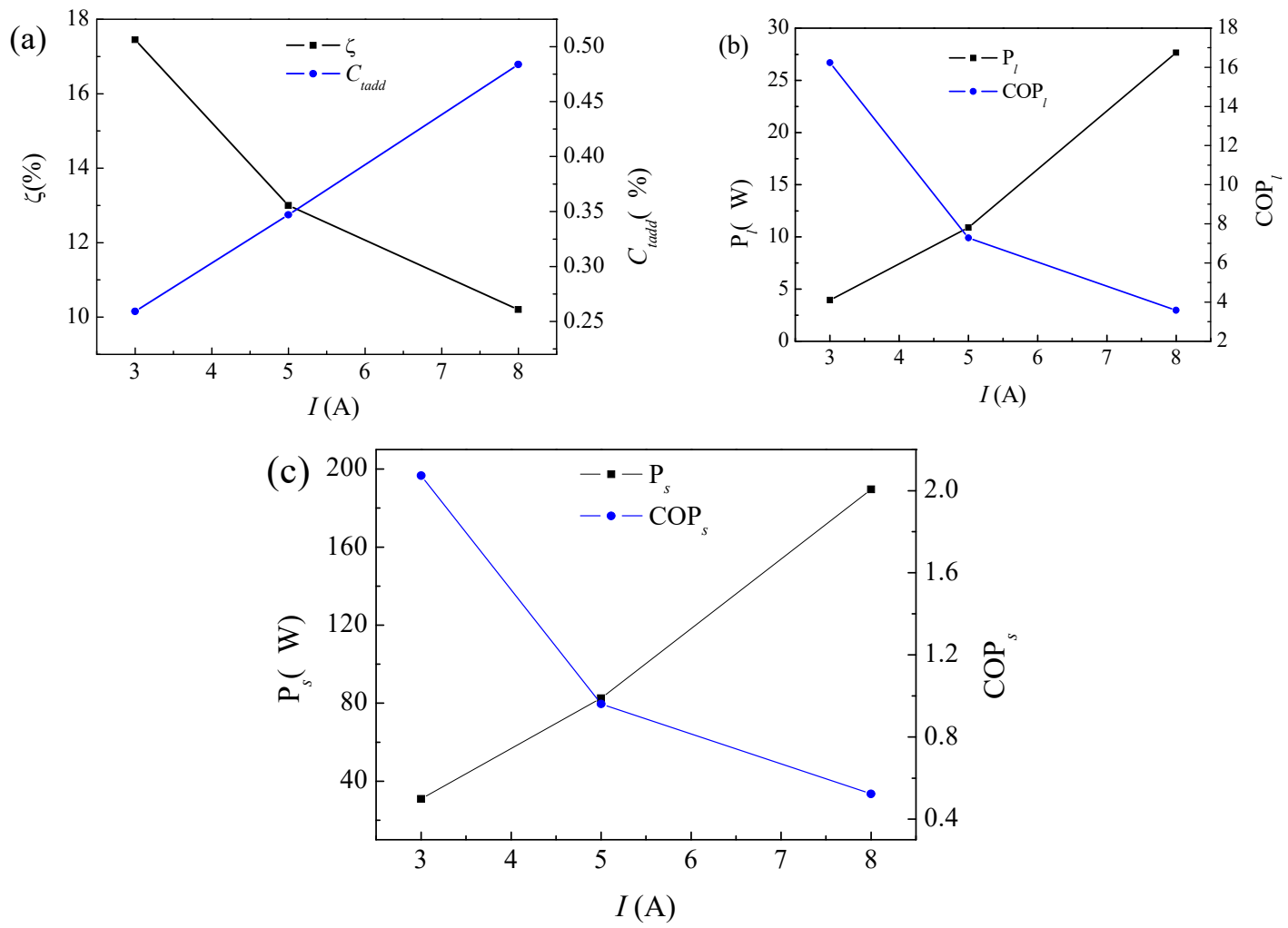

Figure 5. (a) The effect of current on the performance of the electrodialyzer; (b) the effect of current on the performance of the electrodialysis regeneration system under theoretical conditions; (c) the effect of current on the performance of the electrodialysis regeneration system under test conditions.

\subsection{Effect of Electrode Solution}

Figure 6a shows the regeneration performance of the electrodialyzer using different electrode solutions with different concentrations. It is shown from the figure that, at the concentration of $\mathrm{LiBr}$ solution of $55 \%$, the regeneration performance of the electrodialyzer decreases with the concentration of the electrode solution. When the electrode solution is $\mathrm{LiBr}$ solution with the concentration of $55 \%$, $50 \%, 45 \%$, the concentration difference of $\mathrm{LiBr}$ solutions at the inlet and outlet of regenerate panels in the electrodialysis regenerator is around $0.07 \%, 0.06 \%, 0.05 \%$; when the electrode solution is $\mathrm{Li}_{2} \mathrm{SO}_{4}$ solution with a concentration of $25 \%$, the concentration difference of $\mathrm{LiBr}$ solution at the inlet and outlet of regenerate panels is around $0.04 \%$.

Figure $6 \mathrm{~b}$ shows the regeneration performance of the electrodialysis regenerator with different circulation rates of the electrode solution. It can be seen that, with the change in flow rate of the electrode solution, the regeneration performance of the electrodialyzer decreases continuously. At the flow rate of the electrode solution of 80,120 , and $160 \mathrm{~L} / \mathrm{h}$, the concentration difference of LiBr solution at the inlet and outlet of the regenerate panels is around $0.07 \%, 0.05 \%$, and $0.04 \%$. This is because the increase in the circulating flow rate in the electrode panels enhances the migration process of the water molecules in the electrode solution to the $\mathrm{LiBr}$ solution in the regeneration panels. 


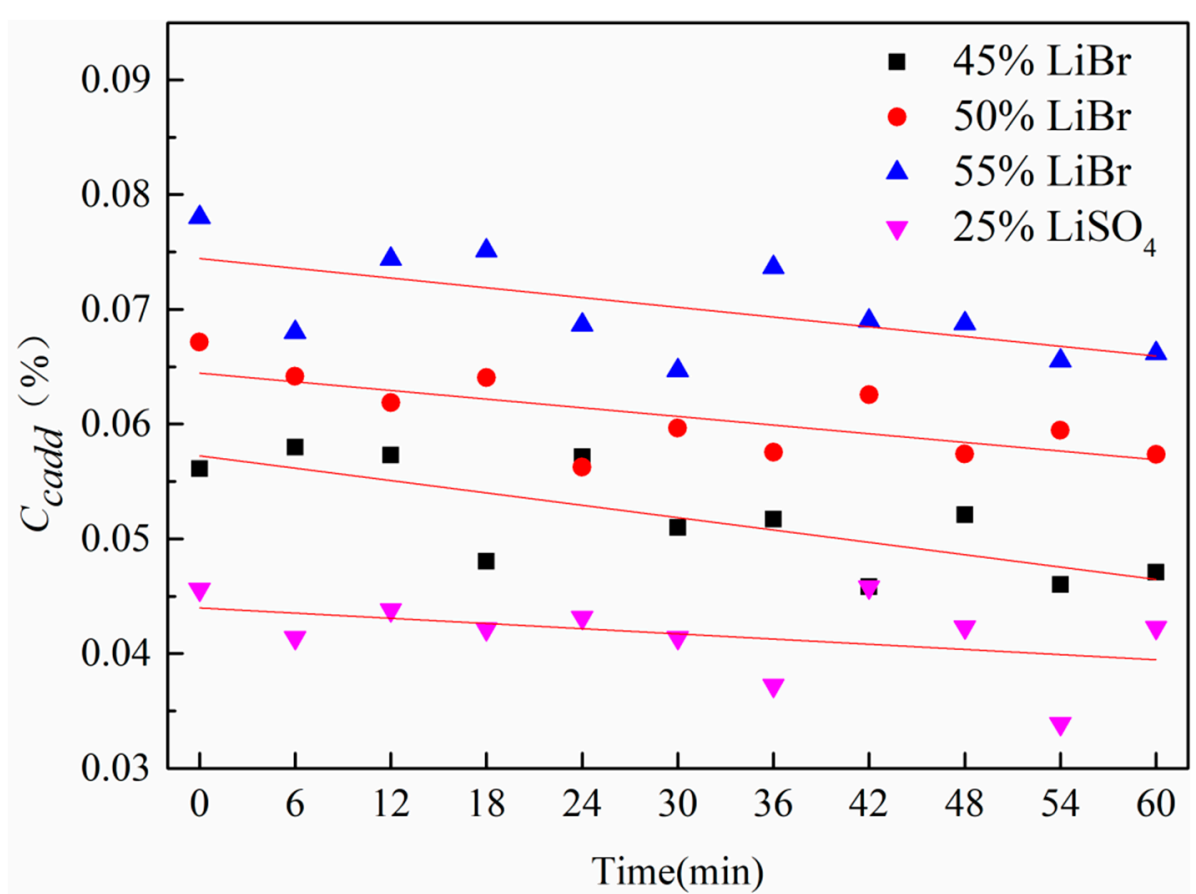

(a)

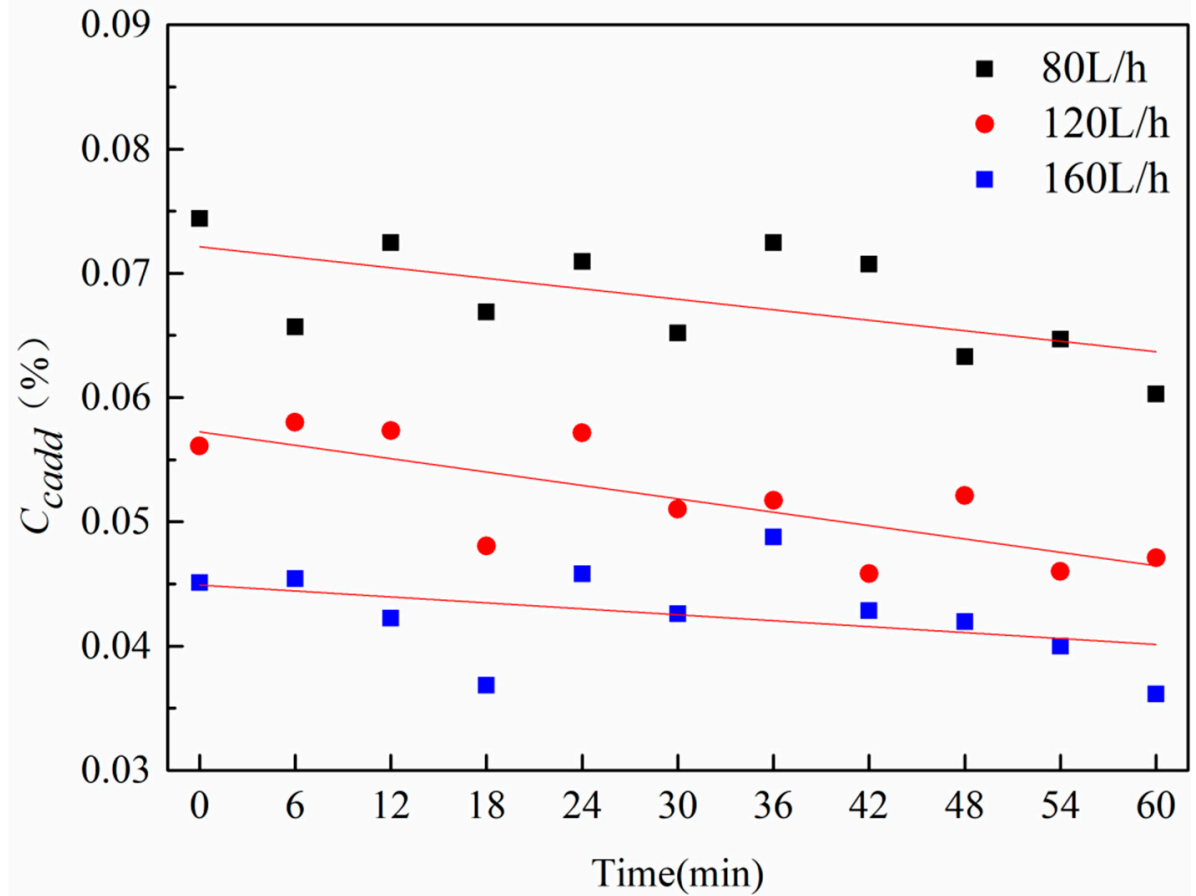

(b)

Figure 6. The effect of electrode solution. (a) The effect of concentration of electrode solution. (b) The effect of flow rate of electrode solution.

\subsection{Temperature Change of the Regeneration Tank Solution}

Figure 7 shows the relationship between the operating current and the temperature change of the regenerate desiccant solution. The hot liquid desiccant shows weak dehumidification performance in the dehumidifier, so the increase of liquid desiccant temperature is harmful to the dehumidification performance and the hot liquid desiccant should be cooled before it enters the dehumidifier. As a result, both concentration and temperature of liquid desiccant after regeneration should be researched to evaluate the performance of the ED regenerator. 


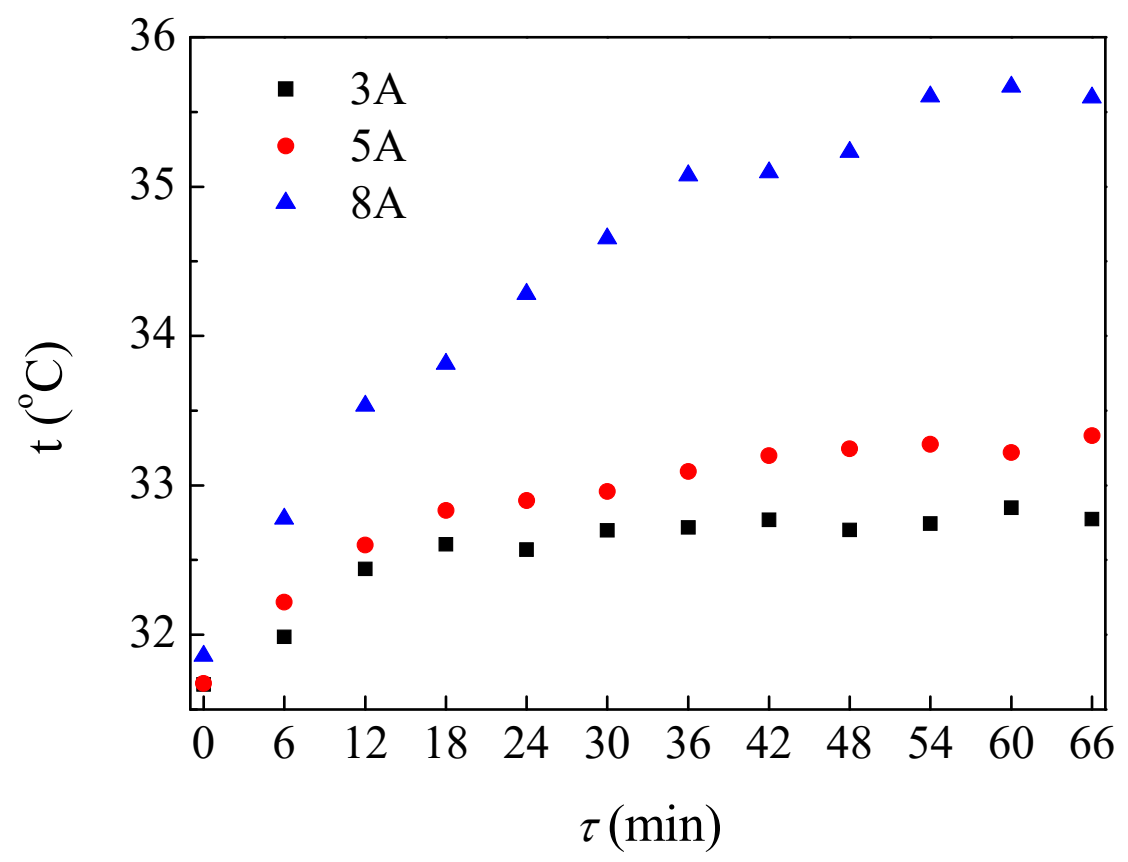

Figure 7. Effect of current on temperature of lithium bromide regeneration solution.

It is concluded that, when the current increases, the temperature difference of the regenerate desiccant solution increases continuously at the end of the test; when the current is 3,5, and $8 \mathrm{~A}$, the temperature of the regeneration solution increases by $1.1,1.6$, and $3.7^{\circ} \mathrm{C}$, respectively. As we can see from the figure, the temperature of the regenerate solution will keep constant after rapidly increasing at the beginning of the test. When an electrodialyzer is used to regenerate LiBr solution, the solution temperature rise is limited, and the desiccant solution does not need to be cooled before entering the dehumidifier, which decreases the system energy consumption.

Under the same current conditions, the concentration and flow rate of the desiccant liquid have little effect on the temperature of the regeneration solution, so they are not listed here.

\subsection{Discussion}

As the research result is based on the experimental result, the results of this research can be employed with conditions including currents varying from 3 to $8 \mathrm{~A}$, flow rates of liquid desiccant varying from 80 to $160 \mathrm{~L} / \mathrm{h}$, and mass concentrations of $\mathrm{LiBr}$ solution varying from $25 \%$ to $55 \%$. The experimental result shows that, with the increase in the concentration of the liquid desiccant, more electrolytic gas will be generated at the electrodes, resulting in an increase in resistance, which is not considered in the theoretical conditions. Therefore, when an electrodialyzer is used to regenerate the desiccant solution, the initial concentration of the LiBr solution should be minimized to make the electrodialysis regeneration system have ideal performance under the premise of meeting the needs of dehumidification. Although increasing the current can improve the regeneration effect, the energy consumption of the electrodialysis regeneration system for $\mathrm{LiBr}$ solution is greatly increased. Therefore, when the regeneration requirement is met, the applied current should be minimized. Meanwhile, when the concentration of $\mathrm{LiBr}$ solution in the regeneration panels is higher than that of the electrode solution, the solution in the regeneration panels will penetrate into the electrode panel, thereby leading to a drop in the regeneration performance of the electrodialyzer. There is a major difference between theoretical and experimental values in this paper-this is mainly because the resistance of electrode chambers and electrodes is neglected in the theoretical analysis, but the comparative results show that the resistance of electrode chambers is also important for the ED regenerator, as is the huge gas production in electrode chambers resulting from the large operational current. Consequently, it is important to evaluate the resistance of electrode chambers in the ED regenerator in the future work. 


\section{Conclusions}

In this paper, an experimental system of electrodialysis regeneration for $\mathrm{LiBr}$ solution was established, and the effects of solution concentration, flow rate, current, and electrode solution on the regeneration performance of electrodialysis and the performance of an air conditioning system dehumidified by solution based on ED regeneration were studied. The results are as follows:

1. Increasing the starting concentration of the $\mathrm{LiBr}$ solution adversely affects the regeneration performance of the electrodialyzer and the characteristic of the air conditioning system dehumidified by the solution. When the dehumidification requirement is met, the initial concentration of the LiBr solution should be reduced.

2. Increasing the circulating flow rate can improve the regeneration performance of the electrodialyzer and the characteristic of the air conditioning system dehumidified by the solution, but excessively increasing the flow rate will reduce the regeneration performance of the electrodialyzer and the performance of the air conditioning system dehumidified by the solution.

3. Increasing the operating current can increase the concentration of the $\mathrm{LiBr}$ solution in the concentration cells in a short time, but it will reduce the regeneration performance of the electrodialyzer and the characteristic of the air conditioning system dehumidified by the solution. The current needs to be minimized when meeting regeneration requirements.

4. Through theoretical analysis and experimental research, it is found that the theoretical performance of the air conditioning system dehumidified by the solution is much larger than the experimental value, which is mainly because the theoretical power consumption of the system is much smaller than the experimental value. This shows that seeking to lower the energy consumption of the electrodialysis system is a method by which to improve the performance of electrodialysis in the future.

5. With the increase in the flow rate of the electrode solution, the regeneration performance of the electrodialyzer decreases continuously.

6. When the electrodialyzer regenerates the $\mathrm{LiBr}$ solution, the temperature rise of the $\mathrm{LiBr}$ solution is small. Therefore, the $\mathrm{LiBr}$ solution does not need to be pre-cooled before entering the dehumidifier, which decreases the system's energy consumption.

Author Contributions: Investigation, H.W.; methodology, Q.C. All authors have read and agreed to the published version of the manuscript.

Funding: This research was funded by (Jiangsu Province Key Laboratory of Aerospace Power System) grant number (CEPE2018002)

Conflicts of Interest: The authors declare no conflict of interest.

\section{References}

1. Lin, W.; Ma, Z.; Sohel, M.I.; Cooper, P. Development and evaluation of a ceiling ventilation system enhanced by solar photovoltaic thermal collectors and phase change materials. Energy Convers. Manag. 2014, 88, 218-230. [CrossRef]

2. Kreiner, H.; Passer, A.; Wallbaum, H. A new systemic approach to improve the sustainability performance of office buildings in the early design stage. Energy Build. 2015, 109, 385-396. [CrossRef]

3. Jiang, X.; He, H.; Li, X.; Mao, H. Performance analysis and mixing ratio selection of mixed liquid desiccant for a dehumidification system. Indoor Built Environ. 2020, 29, 711-720. [CrossRef]

4. Guo, Y. Electrodialysis-Assisted Liquid Desiccant Dehumidification: Experimental Investigation and System Development. Ph.D. Thesis, University of Wollongong, Wollongong, Australia, 2017. Available online: https://ro.uow.edu.au/theses1/114 (accessed on 10 September 2020).

5. Duong, H.; Ansari, A.; Nghiem, L.; Cao, H.; Vu, T.; Nguyen, T. Membrane processes for the regeneration of liquid desiccant solution for air conditioning. Curr. Pollut. Rep. 2019, 5, 308-318. [CrossRef]

6. Duong, H.; Hai, F.; Al-Jubainawi, A.; Ma, Z.; He, T. Liquid desiccant lithium chloride regeneration by membrane distillation for air conditioning. Sep. Purif. Technol. 2017, 177, 121-128. [CrossRef] 
7. Niu, X.; Xiao, F.; Ma, Z. Investigation on capacity matching in liquid desiccant and heat pump hybrid air-conditioning systems. Int. J. Refrig. 2012, 35, 160-170. [CrossRef]

8. Elsarrag, E. Evaporation rate of a novel tilted solar liquid desiccant regeneration system. Sol. Energy 2008, 82, 663-668. [CrossRef]

9. Galama, A.H.; Saakes, M.; Bruning, H.; Rijnaarts, H.H.M.; Post, J.W. Seawater predesalination with electrodialysis. Desalination 2014, 342, 61-69. [CrossRef]

10. Valero, D.; García-García, V.; Expósito, E.; Aldaz, A.; Montiel, V. Application of electrodialysis for the treatment of almond industry wastewater. J. Membr. Sci. 2015, 476, 580-589. [CrossRef]

11. Li, X.; Zhang, X. Photovoltaic-electrodialysis regeneration method for liquid desiccant cooling system. Sol. Energy 2009, 83, 2195-2204. [CrossRef]

12. Cheng, Q.; Zhang, X.; Li, X. Double-stage photovoltaic/thermal ED regeneration for liquid desiccant cooling system. Energy Build. 2012, 51, 64-72. [CrossRef]

13. Cheng, Q.; Zhang, X.; Jiao, S. Experimental comparative research on electrodialysis regeneration for liquid desiccant with different concentrations in air-conditioning system dehumidified by solution. Energy Build. 2017, 155, 475-483. [CrossRef]

14. Cheng, Q.; Zhang, X.; Jiao, S. Influence of concentration difference between dilute cells and regenerate cells on the performance of electrodialysis regenerator. Energy 2017, 140, 646-655. [CrossRef]

15. Cheng, Q.; $\mathrm{Xu}, \mathrm{W}$. Performance analysis of a novel multi-function liquid desiccant regeneration system for air-conditioning system dehumidified by solution. Energy 2017, 140, 240-252. [CrossRef]

16. Al-Jubainawi, A.; Ma, Z.; Guo, Y.; Nghiem, L.D.; Cooper, P.; Li, W. Factors governing mass transfer during membrane electrodialysis regeneration of $\mathrm{LiCl}$ solution for liquid desiccant dehumidification systems. Sustain. Cities Soc. 2017, 28, 30-41. [CrossRef]

17. Li, X.; Zhang, X. Membrane air-conditioning system driven by renewable energy. Energy Convers. Manag. 2012, 53, 189-195. [CrossRef]

18. Liu, X.H.; Yi, X.Q.; Jiang, Y. Comparison of Mass Transfer Performance of Two Common Liquid Hygroscopic Agents. J. Chem. Ind. Eng. 2009, 60, 567-573.

19. Guo, Y.; Ma, Z.; Al-Jubainawi, A.; Cooper, P.; Nghiem, L.D. Using electrodialysis for regeneration of aqueous lithium chloride solution in liquid desiccant air conditioning systems. Energy Build. 2016, 116, 285-295. [CrossRef] 